\title{
Prasasti Batu Jimbar di Dusun Bet Ngandang Desa Intaran: Kajian Epigrafi
}

\author{
Ni Putu Kurnia Saraswati ${ }^{1^{*}}$, Ida Bagus Saptajaya ${ }^{2}$ \\ ${ }^{[123]}$ Prodi Arkeologi, Fakultas Ilmu Budaya, Unud \\ ${ }^{1}$ [niasaraswati92@yahoo.com], ${ }^{2}$ [bagus-sapta@yahoo.com] \\ *Corresponding Author
}

\begin{abstract}
Abstrak
Studi ini bertujuan untuk mengetahui aspek kebahasaan prasasti Batu Jimbar yang meliputi aksara, bahasa, ejaan, dan afiksasi. Selanjutnya untuk mengetahui aspek sosial budaya yang terkandung dalam prasasti tersebut. Metode pengumpulan data yang digunakan dalam penelitian ini ialah observasi, studi pustaka, dan wawancara dengan pengolahan data melalui analisis kualitatif, interpretatif, dan epigrafi. Berdasarkan hasil analisis dari prasasti Batu Jimbar dapat diketahui prasasti ini menggunakan huruf Bali Kuno dengan bahasa Jawa Kuno. Prasasti Batu Jimbar menggunakan ejaan yang telah berkembang pada masa sebelumnya seperti : prefix (awalan) para-, ma-, pa-, ka-, sa-, um-, a-, dan ha-, Sufiks (akhiran) -ěn, -nya, -an, dan konfiks (pa- + -ma), (ma- + -an), (a- + -an), (ka- +-an), (ka- +-nya), (maka + - an). Aspek sosial budaya yang termuat dalam prasasti Batu Jimbar ialah mengenai hak dan kewajiban serta organisasi sosial yang ada didalamnya seperti mengenai hak dan kewajiban yang harus dilaksanakan oleh penduduk Indrapura dengan memuja Bhatara di Bukit Tunggal.
\end{abstract}

Kata kunci: prasasti Batu Jimbar, bahasa, sosial budaya

\begin{abstract}
The purposed this study is to know linguistic aspects of the Batu Jimbar inscription which includes script, language, spelling, and affixation. Furthermore, the research also discussed about the social aspects contained. Data collection methods used in this study were observation, literature study, and interviews with data processing through qualitative, interpretative, and epigrafi analysis. Based on the analysis of Batu Jimbar inscription, it can be known that the inscription used the ancient Balinese letters with the Old Javanese language. Batu Jimbar inscription used spellings that had been developed in the previous era, such as prefixes para-, ma-, pa-, ka-, sa-, um-, a-, and ha-, suffixes - én, -nya, -an, and confixes (pa- + -ma), (ma- + -an), (a- + -an), (ka- + an), ( ka- + -nya), (maka + -an). Socio-cultural aspects contained in the Batu Jimbar inscription is about the rights and obligations and social organizations that exist in it such as the rights and obligations that must be implemented by Indrapura residents by worshiping Bhatara (Gods) at Bukit Unggal (Hill).
\end{abstract}

Keywords: Batu Jimbar inscription, language, socio-culture.

\section{Latar Belakang}

Prasasti merupakan salah satu tinggalan arkeologi tekstual yang tertulis di atas bahan yang keras seperti batu dan logam, biasanya memuat rekaman mengenai berbagai aspek kehidupan manusia masa lalu. Prasasti ini berasal dari masa klasik dimana manusia telah mengenai tahap literate culture sehingga kronologi historisnya dapat diketahui melalui kronologi waktu. Penyelidikan prasasti dapat mengungkapkan berbagai hal menyangkut kehidupan dari masyarakat zaman dahulu mengenai 
sosial ekonomi, teknologi, organisasi sosial, kesenian, dan sistem kepercayaan (Wibisono, 2006: 1).

Prasasti pada umumnya dikeluarkan oleh seorang raja. Di dalamnya biasanya disebutkan mengenai sebab-sebab prasasti itu dikeluarkan yang merupakan inti isi prasasti itu yaitu penetapan suatu daerah, pendirian suatu bangunan suci atau bangunan lainnya, masalah atau perkara perdata, dan masalah-masalah lainnya. Kemudian pada bagian lain dari prasasti tersebut ditetapkan mengenai ketentuan hak dan kewajiban masyarakat setempat. Sesungguhnya prasasti tersebut merupakan sebuah dokumen yang memuat undang-undang atau peraturan pemerintah untuk mengatur hidup masyarakat pada saat itu.

Prasasti yang dikeluarkan oleh seorang raja dianggap sebagai anugerah yang diturunkan oleh raja. Anugerah tersebut dapat berupa hak-hak tertentu sekaligus kewajiban yang melekat di dalamnya seperti hak mengelola bangunan suci, hak penguasaan suatu daerah, hak pemilikan atas tanah, pembebasan sebagian dan keseluruhan pajak yang dibebankan, dan lain sebagainya. Aturan-aturan yang dimuat dalam suatu prasasti harus dipatuhi dan dijaga oleh masyarakat hingga kelak kemudian hari. Kesemuanya itu disertai dengan upacara tertentu yang disaksikan oleh pejabat-pejabat tertentu dari tingkat pusat. Selanjutnya pada bagian akhir prasasti biasanya dicantumkan sapatha yang memuat mengenai kutukan bagi mereka yang berani melanggar titan raja tersebut (Tim Penyusun Dinas Kebudayan Kota Denpasar, 2015: 1).

Salah satu kelompok prasasti yang ditemukan di Bali ialah prasasti yang ditemukan di Dusun Bet Ngandang Sanur pada tahun 1988. Saat ini Bet Ngandang merupakan sebuah nama kawasan yang berada di pesisir pantai selatan pulau Bali yang secara administratif terletak di wilayah Desa Pekraman Intaran Sanur Kauh, Denpasar Selatan. Prasasti ini berjumlah enam lempeng yang terbagi atas dua kelompok. Kelompok I terdiri atas lima lempeng tembaga sedangkan kelompok II hanya terdiri atas satu lempeng tembaga. Prasasti ini tersimpan di dalam pelinggih Gedong dirumah salah seorang penduduk Banjar Batu Jimbar, Bet Ngandang Desa Pekaraman Intaran Sanur Bapak I Nyoman Sumariana.

Penelitian yang akan dilakukan dalam studi ini meliputi aspek kebahasaan Batu Jimbar belum pernah dibahas oleh penelitian terdahulu danaspek sosial budaya yang termuat dalam prasasti tersebut.

\section{Pokok Permasalahan}

Berdasarkan apa yang telah dijelaskan dalam latar belakang permasalahan, muncul beberapa pertanyaan adalah sebagai berikut.

1. Bagaimana aspek kebahasaan Prasasti Batu Jimbar, khususnya terkait ejaan, bahasa, dan afiksasi dari prasasti Batu Jimbar?

2. Aspek sosial budaya apa saja yang termuat dalam prasasti Batu Jimbar?.

\section{Tujuan Penelitian}

Adapun tujuan dari penelitian ini, sebagai berikut. 1) Untuk mengetahui aspek kebahasaan yang meliputi ejaan, aksara, dan isi yang termuat dalam prasasti Batu Jimbar. 2) Untuk mengetahui aspek sosial budaya yang termuat dalam prasasti Batu Jimbar.

\section{Metode Penelitian}

Jenis penelitian yang digunakan dalam studi ini adalah kualitatif, yakni secara umum data yang digunaka bersumber dari tekstual dan hasil yang ditampilkan berupa kalimat, pernyataan, atau katakata. Penelitian ini berlokasi di Banjar 
Bet Ngandang, Desa Pekraman Intaran Sanur Kauh, Denpasar Selatan tepatnya dirumah milik Bapak Nyoman Sumariana. Secara administratif, Dusun Bet Ngandang merupakan bagian dari Desa Pekraman Intaran Sanur Kauh, Denpasar Selatan dengan jarak tempuh dari pusat kota kurang lebih 10 kilo meter.

Teknik pengumpulan data yang digunakan dalam penelitian ini yaitu: Studi pustaka, observasi, dan wawancara. Setelah data terkumpul tahap berikutnya ialah analisis. Analisis yang digunakan adalah kualitatif, komparatif, dan epigarfi. Analisis kualitatif disajikan dalam bentuk deskriptif yang terdiri atas aspek intern (non fisik prasasti) dan aspek ekstern (fisik prasasti). Analisis interpretative merupakan analisis yang mengandalkan interpretasi dan penafsiran-penafsiran sasaran penelitian dengan harapan diperolehnya fakta-fakta yang bersifat umum. Analisis ini digunakan untuk menginterpretasi atau menafsirkan terkait dengan sosial budaya yang termuat dalam prasasti Batu Jimbar.

Analisis epigarfi, epigrafi ialah ilmu tentang tulisan-tulisan di atas bahan kertas, batu dan logam beserta tafsirannya (Bakker, 1972: 10). Ahli epigrafi disebut epigraf dengan objek studi utama adalah prasasti dan piagam. Oleh karena itu analisis epigrafi menyangkut dengan tulisan-tulisan yang termuat dalam prasasti. Analisis ini digunakan untuk mengetahui tulisan, aksara, bahasa, ejaan dan afiksasi yang termuat dalam prasasti Batu Jimbar.

\section{Hasil dan Pembahasan \\ 5.1 Aspek Kebahasaan \\ Bahasa}

Pada masa pemerintahan Anak Wungsu pengaruh kebudayaan Jawa tampak bertambah kuat hal tersebut dapat dilihat dari penggunaan bahasa. Prasasti yang bertuliskan Bahasa Bali Kuno kemudian disalin dalam bahasa Jawa Kuno sehingga pemakaian bahasa Jawa Kuno menjadi suatu kebiasaan di Bali. Kondisi seperti itu menyebabkan Bahasa Bali Kuno (khususnya ragam tulis) nyaris tidak terpakai. Seiring dengan perkembangan Bahasa Bali Kuno secara perlahan digantikan dengan bahasa Jawa Kuno. Bahasa Jawa Kuno mulai berkembang di Bali semenjak adanya hubungan antara Jawa dan Bali.

Hubungan tersebut dimulai ketika Raja Dharmodhayana Warmadewa yang dikenal dengan Udayana memperistri Sri Gunapriyadharmapatni yang merupakan seorang putri dari tanah Jawa yang dikenal dengan sebutan Mahendradatta. Perkawinan tersebut menjadikan Jawa dan Bali memiliki hubungan yang semakin erat. Gunapriyadharmapatni memiliki pengaruh yang sangat besar di Bali, dimulai dari salah satu unsur kebudayaan Jawa yaitu bahasa. Pada masa pemerintahan Raja Dharmodayana Warmadewa dan Sri Gunapriyadharmapatni diterbitkan sebanyak lima buah prasasti yakni dua prasasti Bebetin A II berangka tahun 911 Saka dan prasasti Serai AII berangka tahun 915 dengan bahasa Bali Kuno.

Selanjutnya tiga prasasti lainnya ialah prasasti Bwahan A dengan angka tahun 916 Saka, prasasti Sading berangka tahun 923 Saka, dan prasasti Pura Abang A berangka tahun 933 Saka dengan menggunakan bahasa Jawa Kuno (Surasmi, 1994: 120). Dilihat dari hal tersebut maka Sang Ratu memiliki peranan yang sangat penting dalam pemerintahan. Terlebih lagi dalam prasasti yang dikeluarkan pada masa pemerintahannya selalu menyebutkan nama Mahendradatta terlebih dahulu, baru kemudian disusul dengan nama Raja Udayana. Mardiwarsito dan Kridalaksana (1984: 29) menyebutkan bahwa Bahasa Jawa Kuno nampaknya sangat di pengaruhi oleh Bahasa Sanskerta, yang 
dapat dilihat dari cara mengeja seperti dalam membedakan panjang atau pendeknya suatu vokal yang dilambangkan dengan huruf : a-ā,i-i, u- $\overline{\mathrm{u}}$, fonem beraspirasi seperti : bh, dh, kh, p, th, dan sebagainya, serta bunyi desis pikal dan palatal (ş dan ś).

Berdasarkan hasil penelitian ini dinyatakan bahwa prasasti Batu Jimbar, yang diduga dikeluarkan oleh Raja Jayasakti menggunakan Bahasa Jawa Kuno. Hal tersebut membuktikan penggunaan Bahasa Jawa Kuno pada masa pemerintahan Anak Wungsu semakin berkembang hingga masa Jayasakti dan raja lainnya.

\section{Ejaan}

Prasasti Batu Jimbar menggunakan bahasa Jawa Kuno yang sangat dipengaruhi oleh bahasa Sanskerta. Pengaruh tersebut tampak dalam cara mengeja, seperti halnya dalam membedakan panjang pendek vokal yang dilambangkan dengan huruf : $a-\bar{a}, i-\overline{1}, u-\bar{u}$, fonem beraspirasi seperti bh, dh, kh, ph, th, dan sebagainya, serta bunyi desis apikal dan palatal (s dan $s$ ). Bunyi-bunyi yang digambarkan oleh huruf-huruf tersebut bukan merupakan bunyi bahasa Jawa Kuno asli, melainkan penulisannya tetap menurut pola ejaan Sanskerta.Ucapan-ucapan dalam bahasa Sanskerta tidak selalu sama dengan bahasa-bahasa Nusantara sehingga menimbulkan masalah dalam usaha penulisan abjad tersebut.

Dalam studi ini ejaan meliputi penggunaan $\check{e}$ pěpět, vokal panjang, pemakaian vokal rangkap/diptong, dan penggunaan konsonan. Pada prasasti Batu Jimbar terdapat beberapa cara

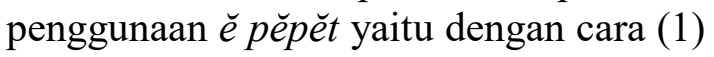
penggunaan tanda $\breve{~}$ pépět itu sendiri, (2) merangkapkan konsonan dari kata dasar. Pemakaian vokal panjang yang terlihat hanya untuk vokal $a$ saja, huruf vokal lainnya seperti i, u, e dan o tidak ditemukan. Penggunaan vokal rangkap atau diphthong terlihat dalam beberapa kata antara lain (a) vokal rangkap a+i: e, (b) vokal rangkap u+a: w, (c) vokal rangkap $\mathrm{a}+\mathrm{u}$ : $\mathrm{o}$. penggunaan konsonan cenderung memisahkan antara satu kata dengan kata lainnya.Hal ini terlihat ketika satu kata yang diakhiri huruf konsonan disertai wirama atau adegadeg.

\section{Afiksasi}

Afiksasi merupakan proses morfologis dalam pemberian imbuhan pada kata dasar yang akan menghasilkan kata berimbuhan. Imbuhan tersebut terdiri dari awalan (prefiks), sisipan (infiks), akhiran (sufiks), dan imbuhan gabungan (konfiks). Jenis- jenis imbuhan yang terdapat pada prasasti Batu Jimbar antara lain :

1. Awalan (prefiks) : $k a-, m a-$, $a-, p a-, s a-$

2. Sisipan (infiks) : $-u m-,-i n-$

3. Akhiran (sufiks) : -an, - ̌̆n, nya

4. Konfiks $:(p a+a n)$, $(k a+a n)$.

\subsection{Aspek Sosial Budaya Aspek Perpajakan}

Dari lima lempeng prasasti Batu Jimbar dapat diketahui bahwa masyarakat telah mengenal beberapa jenis pajak maupun iuran dengan aktivitas mereka. Pajak profesi, dalam prasasti dapat memberikan keterangan mengenai sekelompok warga desa yang diwajibkan membayar pajak pada pemerintah, biasanya mereka disebut dengan wargya kilalan yang terdiri dari orang asing dan orang yang memeliki profesi tertentu kecuali orang- orang keturunan asing. disebut dalam prasasti Batu Jimbar pada hari pertama dibulan terang masyarakat tidak dikenai berbagai jenis persembahan termasuk dengan segala jenis pajak seperti pacaksu 
(sejenis pajak) pangiwo (sejenis iuran untuk pemeliharaan ?) , dan juga tidak dikenakan pangleyö (sejenis iuran ?), palaris (sejenis iuran).....'. Selain profesi sebagai pengawas, juga terdapat jenis pajak yang berhubungan dengan profesi sebagai pemadam kebakaran yang disebut dengan istilah pepadem.Padam berarti 'mati atau tidur' (Granoka dkk, 1985: 76).

Pada masa pemerintahan raja Ugrasena serta pada masa pemerintahan Raja Udayana sudah dikenal dengan adanya pekerjaan membuat perahu.Bahkan mereka dikenakan kewajiban untuk menjaga perahu (lancang).Akan tetapi dalam prasasti Batu Jimbar tidak dikenakan kewajiban untuk membuat maupun menjaga perahu tersebut. Sedangkan pajak peternakan yang termuat dalam prasasti Batu Jimbar hal tercermin dalam kata Pangiwö, yakni pajak untuk berasal dari kata iwo yang berarti pelihara, dan ternak, kembang biak.

Pajak perdagangan tercermin dalam kutipan pinta panumbas merupakan jenis pajak/iuran yang terkait dengan pembelian dan penjualan. Selain itu iuran keagamaan meliputi pamapas merupakan iuran atau pungutan kepada masyarakat untuk saji-sajian, haywahaywa dapat diartikan sebagai pemberian berupa barang-barang, Caru bisa diartikan sebagai pajak atau iuran yang dipungut untuk upacara kurban, dan prayasçita merupakan iuran terkait sesajen karena terjadi suatu hal yang menyimpang.

\section{Organisasi Sosial}

Pada sistem pemerintahan kerajaan Bali Kuno, kekuasaan dan wewenang seorang raja sangat terlihat jelas dari peninggalan- peninggalan prasastinya. Hal tersebut terlihat pada puncak pemerintahan Bali Kuno yang dipegang oleh raja yang bergelar haji atau maharaja yang juga di damping oleh para permaisurinya sebagai tanda bahwa rakyat menghormati dan menempatkan permaisuri baginda sesuai dengan kedudukan raja. Kedudukan seorang raja dalm suatu pemerintahan Bali Kuno sangatlah penting, dihormati, dan diutamakan, karena pada masa itu raja yang berkuasa dianggap sebagai titisan dewa yang mengayomi dan melindungi keluarga dan rakyatnya.

Raja dalam menjalankan pemerintahan tidaklah bersifat oteriter, dalam menjalankan pemerintahan Raja berkonsultasi dengan lembaga tinggi kerajaan atau badan penasehat tingkat pusat, para ulama dan pejabat tingkat desa, yang kesemuanya merupakan perangkat pemerintahan dan membentuk suatu sistem tersendiri. Raja dalam mengambil suatu keputusan selalu atas dasar musyawarah dengan pejabatpejabatnya, sehingga pada masa Bali Kuna sudah mengenal demokrasi yang secara tidak langsung diterapkan (Ardika dkk, 2013: 138). Oleh karena itu tugas tugas dari seorang raja sangatlah banyak maka dibentuklah semacam struktur pemerintahan yang terdiri atas jumlah jabatannya.Berdasarkan istilah yang dipakai dan kewenangannya, maka secara garis besar jabatan- jabatan tersebut dapat dikategorikan menjadi jabatan struktural dan jabatan fungsional.

Jabatan struktural Berdasarkan hirarkinya atau garis pemerintahnnya dan wilayah kekuasaanya dapat dipilih menjadi : a). jabatan tingakt pusat dan, b). jabatan tingkat desa. Jabatan tingkat pusat meliputi raja, Dalam prasasti Batu Jimbar nama seorang raja tidak disebutkan di dalamnya, hal tersebut dapat disebabkan karena kaadan prasasti yang kurang lengkap. Namun beberapa hasil penelitian terdahalu menyebutkan bhawa prasasti Batu Jimbar meupakan hasil kebudayaan dari Pāduka Śrī Mahārāja Śr rī Jayaśakti. Beliau 
memerintah pada tahun 1055 Saka-1071 Saka (1133-1149 Masehi.

Senapati berasal dari bahasa Sansekerta sen $\bar{a}$ yang berarti tentara dan pati berate raja. Jadi senāpati merupakan raja atau pemimpin tentara.Jika seseorang menduduki jabatan senāpati tidaklah semata- mata bertugas dan hanya berwenang sebagai pemimpin tentara. Dalam prasasti Batu Jimbar senapati merupakan jabatan terhormat dan merupakan kepercayaan dari raja untuk mengatur dan mengurus semua yang diperintahkan oleh raja.

Kelompok samgat biasanya disebutkan setelah kelompok senapati dan terdiri atas beberapa jabatan. Tugas dan wewenang jabatan samgat pun belum diketahui dengan pasti. Kata samgat dipandang sebagai akronim dari kata sang pamgat. Kata pamgat terbentuk atas kata dasar pgat dengan prefiks $p a$. Pamgat berarti "pemutus" dan samgat dapat diartikan sebagai "sang pemutus" (Ardana dkk, 2012: 34).

Mpungkwing merupakan jabatan yang memiliki tugas dan kewenangan mengatur dibidang keagamaan.Jabatan ini dijabat oleh para pemuka agama Siwa dan agama Budha. Kedua pendeta selalu dimintai doa restunya dengan sangat agar tercapainya ketentraman seluruh rakyat dan negaranya. Kelompok pendeta tersebut terdiri dari sejumlah pendeta Siwa/Hindu disebut kaçewan dan sejumlah pendeta Budha yang disebut kasogatan. Penyebutan nama para pendeta Siwa/Hindu dalam prasasti disebut Dang Acarya dan untuk para pendeta budha disebut Dang Upadhyaya. Dang merupakan sebuah partikel penunjuk orang yang lazim digunakan untuk orang-orang terhortmat, selanjutnya Acarya berarti 'pendeta, guru agama' dan Upadhyaya berarti 'guru'Dang Acarya dan Dang Upadhyaya pada hakikatnya berarti 'yang terhormat sang guru- guru yang terhormat (Granoka dkk, 1985: 1).

Selain jabatan struktural juga terdapat jabatan fungsional yang kewenangnanya diakui oleh lebih dari satu desa dan bertugas menyelesaikan suatu masalah tertentu secara professional serta bertanggung jawab kepada tanda rakryan. Kata Nayaka dalam Kamus Bali Kuna-Indonesia diartikan 'penunjuk jalan, pemimpin, pahlawan, raja, suami, kepala (jabatan)' (Granoka dkk, 1985: 74). Menurut Van deer Tuuk fungsi jabatan nayaka sama dengan jabatan kabayan dalam sistem pemerintahan masyarakat Bali Kuna yaitu suatu pejabat yang bertugas mengurus dan memelihara tempat suci, sebagai imbalannya diberi hak untuk mengelola (memungut hasil) tanah milik tempat suci atau laba pura. Goris menyebutkan nayaka adalah sejenis pemimpin atau kepala atau pengawas. Casparis menyebutkan nayakan adalah petugas kerajaan yang diberikan kepercayaan untuk memungut pajak dari harta warisan orang-orang yang masih hidup (Ardika dkk, 2013: 148).

Jabatan nayaka bila dihubungan dengan drawyahaji diartikan sebagai kepala atau pemimpin atau pengawas pada satu bidang. Jabatan yang diduduki oleh kepala dan mempunyai kewenangan dalan urusan tertentu yang secarahierarki berada di bawah ser. Pada prasasti Batu Jimbar hanya sebagian saja disebutkan kata nayaka kemungkinan dikarenakan prasasti tersebut tidak lengkap.

\section{Simpulan}

Prasasti Batu Jimbar yang diduga dikeluarkan oleh Raja Jayasakti menggunakan Bahasa Jawa Kuno. Hal tersebut membuktikan penggunaan Bahasa Jawa Kuno pada masa pemerintahan Anak Wungsu semakin berkembang hingga masa Jayasakti dan raja lainnya. Dalam studi ini ejaan yang 
digunakan meliputi penggunaan $\breve{e}$ pěpe $\breve{t}$, vokal panjang, pemakaian vokal rangkap/diptong, dan penggunaan konsonan. Pada prasasti Batu Jimbar terdapat beberapa cara penggunaan $\breve{e}$ pépét yaitu dengan cara (1) penggunaan tanda $\breve{e}$ pěpět itu sendiri, merangkapkan konsonan dari kata dasar. Pemakaian vokal panjang yang terlihat hanya untuk vokal $a$ saja, huruf vokal lainnya seperti i, u, e dan o tidak ditemukan.

Penggunaan vokal rangkap atau diphthong terlihat dalam beberapa kata antara lain (a) vokal rangkap a+i: e, (b) vokal rangkap $\mathrm{u}+\mathrm{a}: \mathrm{w},(\mathrm{c})$ vokal rangkap $\mathrm{a}+\mathrm{u}$ : o. penggunaan konsonan cenderung memisahkan antara satu kata dengan kata lainnya.Hal ini terlihat ketika satu kata yang diakhiri huruf konsonan disertai wirama atau adeg-adeg. Jenis- jenis imbuhan yang terdapat pada prasasti Batu Jimbar antara lain : (a) Awalan (prefiks) : $k a-, m a-, a-, p a-, s a-$, (b) Sisipan (infiks) : -um-, -in- (c) Akhiran (sufiks) : -an, -ӗn, -nya, (d) Konfiks $\quad: \quad(p a+a n)$, $(k a+a n)$.

Aspek sosial budaya, aspek ini meliputi perpajakan dan organisasi sosial. Dalam prasasti memberikan keterangan mengenai sekelompok warga desa yang diwajibkan membayar pajak pada pemerintah, biasanya mereka disebut dengan wargya kilalan yang terdiri dari orang asing dan orang yang memeliki profesi tertentu kecuali orang- orang keturunan asing. Disebut dalam prasasti Batu Jimbar pada hari pertama dibulan terang masyarakat tidak dikenai berbagai jenis persembahan termasuk dengan segala jenis pajak seperti pacaksu (sejenis pajak) pangiwo (sejenis iuran untuk pemeliharaan), dan juga tidak dikenakan pangleyö (sejenis iuran), palaris (sejenis iuran).....'. Selain profesi sebagai pengawas, juga terdapat jenis pajak yang berhubungan dengan profesi sebagai pemadam kebakaran yang disebut dengan istilah pepadem. Sedangkan pajak peternakan yang termuat dalam prasasti Batu Jimbar hal tercermin dalam kata Pangiwö, yakni pajak untuk berasal dari kata iwo yang berarti pelihara, dan ternak, kembang biak. Pajak perdagangan tercermin dalam kutipan pinta panumbas merupakan jenis pajak/iuran yang terkait dengan pembelian dan penjualan. Selain itu iuran keagamaan meliputi pamapas merupakan iuran atau pungutan kepada masyarakat untuk saji-sajian, haywahaywa dapat diartikan sebagai pemberian berupa barang-barang, Caru bisa diartikan sebagai pajak atau iuran yang dipungut untuk upacara kurban, dan prayasçita merupakan iuran terkait sesajen karena terjadi suatu hal yang menyimpang.

Jabatan struktural Berdasarkan hirarkinya atau garis pemerintahnnya dan wilayah kekuasaanya dapat dipilih menjadi : a). jabatan tingkat pusat dan, b). jabatan tingkat desa. Jabatan tingkat pusat meliputi tingkat raja, Senapati, samgat, mpungkwing. Selain jabatan struktural juga terdapat jabatan fungsional yang kewenangnanya diakui oleh lebih dari satu desa dan bertugas menyelesaikan suatu masalah tertentu secara professional serta bertanggung jawab kepada tanda rakryan.

\section{Daftar Pustaka}

Ardana, Gusti Gde. 2012 "Aspek-aspek Pemerintahan Prabu Udayana", dalam Seribu Tahun Wafatnya Prabu Udayana. Denpasar: Udayana University Press, halaman: 61-94.

Ardika, I Wayan, I Gde Parimartha, dan AA. Bagus Wirawan. 2015. Sejarah Bali: Dari Prasejarah Hingga Modern. Denpasar: Udayana University Press. 
Bakker, S.J. 1972. Ilmu Prasasti. Yogyakarta: Jurusan Sejarah Budaya IKIP Sanata Dharma.

Granoka, Oka Ida Wayan, I Gde Semadi Astra, I Gusti Ngurah Bagus, I Wayan Jendra, I Nengah Medera, dan Ketut Ginarsa. 1985. Kamus Bali Kuno-Indonesia. Jakarta: Departemen Pendidikan dan Kebudayaan.

Mardiwarsito, L dan Harimurti Kridalaksana. 1984. Struktur Bahasa Jawa Kuna. Flores: Nusa Indah.

Surasmi, I Gusti Ayu. 1994. "Hubungan Jawa-Bali Abad X-XI". Berkala Arkeologi Tahun XIV Edisi Khusus. Yogyakarta: Balai Arkeologi Yogyakarta, hal: 119122.

Tim Penyusun Dinas Kebudayaan Kota Denpasar. 2014. Inventaris Prasasti dan Babad di Kota Denpasar. Denpasar: Dinas Kebudayaan Kota Denpasar.

Wibisono, Anton. 2006. "Perkembangan Aksara Becorak Khusus pada Prasasti-Prasasti Abad XV Masehi": Sebuah Kajian Paleografi". Skripsi. Depok: Universitas Indonesia. 